\title{
The April 2015 Update to RDA and Its Impact on Music Instructions: A Review of What Music Cataloguers Need to Know
}

\author{
by Daniel Paradis and Joseph Hafner
}

\section{Lien vers la version française de l'article}

\section{Abstract}

The April 2015 release of the RDA Toolkit includes major content updates to RDA: Resource Description and Access. Several of the revisions included in the release modify instructions that are used by music cataloguers on a regular basis. This article reviews the most important of these changes with the purpose of making it easier for music cataloguers to navigate the various changes that have taken place in relation to music cataloguing. It examines specifically the impact of the revisions regarding the statement of responsibility, the extent of notated music, the duration, preferred titles of musical works, abbreviations in titles for parts of musical works, and access points representing musical expressions. The article illustrates some of the changes by including examples that were revised or added. It also includes a table which is a comparison of the structure of 6.14.2 instructions before and after the April 2015 update, because of the numerous changes in this area. While this article is aimed primarily at music cataloguers, it could also be of interest to music librarians concerned with cataloguing issues.

\section{Introduction}

According to the schedule established by the Joint Steering Committee for Development of RDA (JSC), the yearly April release of the RDA Toolkit usually includes major content updates to RDA: Resource Description and Access. These updates result from proposals submitted the preceding year by JSC constituencies. The release published on April 14, 2015 is no exception to this practice and includes revisions that were discussed during the November 2014 JSC meeting. Several of the revision proposals approved by the JSC and incorporated in the April 2015 release modify instructions that music cataloguers have to apply on a regular basis. This article

Daniel Paradis is Music Cataloguing Librarian in the Cataloguing Directorate for Heritage Collections (Direction du traitement documentaire des collections patrimoniales) at Bibliothèque et Archives nationales du Québec. He chairs CAML's Cataloguing Committee and is currently a member of the Canadian Committee on Cataloguing, the JSC Music Working Group and the Comité editorial francophone responsible for the translation of RDA into French.

Joseph Hafner is the Associate Dean of Collection Services at McGill University Library, and is in his second term as the Chair of the IAML Cataloguing Commission. He has been a librarian and active with music cataloguing issues since 1989. 
will review the most significant of these changes, ${ }^{1}$ with the goal of informing cataloguers about which instructions were revised or deleted and what these changes mean for them when dealing with music-related materials. Specifically, it will examine the impact of the revisions regarding:

- the statement of responsibility

- the extent of notated music

- the duration

- preferred titles for musical works

- abbreviations in titles for parts of musical works

- access points representing musical expressions

\section{Statement of responsibility}

In RDA a statement of responsibility is defined as "a statement relating to the identification and/or function of any persons, families, or corporate bodies responsible for the creation of, or contributing to the realization of, the intellectual or artistic content of a resource." Strictly speaking, statements identifying performers of music should fall within the scope of this definition, because performers contribute to the intellectual or artistic content of a resource, whether or not they are also responsible, in whole or in part, for creating that content. However, RDA continued the AACR2 practice of permitting statements that identify performers to be transcribed as statements of responsibility only if these performers could, to some degree, be considered as creators of the content. Statements identifying "performers of music whose participation is limited to performance, execution, or interpretation" or "performers, narrators, and/or presenters" had to be recorded in the element "Performer, Narrator, and/or Presenter," which was covered at 7.23. Statements identifying "persons who have contributed to the artistic and/or technical production of a resource" were also treated differently and had to be recorded in the element "Artistic and/or Technical Credit," at 7.24.

However, making distinctions between different types of statements of responsibility could not be justified on principled grounds, even though this could be considered useful for practical reasons. For that reason, the references at 2.4.1.1 guiding cataloguers to 7.23 and 7.24 were deleted, thus expanding the scope of 2.4 .1 to all statements of responsibility. Up to now it was unusual to have names of performers of classical music in statements of responsibility, but this will be changing with this revision. In the field of popular music, jazz, etc., the revision will make

1. The revisions discussed in this article originate from five proposals submitted by the JSC Music Working Group (6JSC/MusicWG/4, 6JSC/MusicWG/5, 6JSC/MusicWG/6, 6JSC/MusicWG/7 and 6JSC/MusicWG/8) and two proposals submitted by the American Library Association (6JSC/ALA/32 and 6JSC/ALA/36). The proposals and related documents, including the responses they elicited from the JSC constituencies, are available on the JSC website at http://www.rda-jsc.org/working1.html\#constituency. 
things easier for cataloguers by eliminating the need to determine if the role of a performer goes beyond mere performance, execution, or interpretation. Examples were added at 2.4.2.3 (Recording Statements of Responsibility Relating to Title Proper) to include statements of responsibility identifying performers, such as this one:

Bach

Emerson String Quartet

Examples were also added at 2.4.1.7 (Clarification of Role) to show that words such as names of instruments can be added to clarify the role of a performer, like this one:

Jorja Fleezanis, Ian Swensen [violins]

Title proper: Quintet for strings in B flat major

7.23.1 and 7.24.1 were revised and now point cataloguers to 2.4 (Statement of Responsibility) and 2.17.3 (Note on Statement of Responsibility) for instructions on recording "a person, family, or corporate body responsible for performing, narrating, and/or presenting a work" or "persons, families, or corporate bodies making contributions to the artistic and/or technical production of a resource." References to chapters 19 and 20 were also added for instructions on recording relationships to these persons, families, and corporate bodies. Sub-instructions 7.23.1.1-7.23.1.3 and 7.24.1.1-7.24.1.3 were deleted, as were the glossary entries for "Artistic and/or Technical Credit" and "Performer, Narrator, and/or Presenter."

Because it was felt that cataloguers would still want the option of recording names of performers or credits in a note instead of transcribing them as statements of responsibility, a paragraph was added at the end of 2.4.2.3 instructing cataloguers to "make a note on persons, families, or corporate bodies not recorded in the statement of responsibility, if considered important for identification, access, or selection (see 2.17.3)." However, a statement considered core for the statement of responsibility related to title proper has to be transcribed as a statement of responsibility and cannot be recorded only in a note.

The text for 2.17.3.5 (Other Information Relating to a Statement of Responsibility) was expanded to accommodate performer notes and notes on credits. It now states that the notes covered by the instruction can include information not recorded in the statement of responsibility element. It also instructs cataloguers to "include a word or short phrase if necessary to clarify the role of a person, family or corporate body named in the note." To illustrate cases where such a note would be useful, examples borrowed from former instruction 7.23.1.3 were added. One of them details which performers are on which side of an audio disc, 
and another gives the name of a string quartet as well as the names of its members, with their instruments:

Recordings by Willie Nelson (side 1), Bob Wills and His Texas Playboys (side 2), Asleep at the Wheel (side 3), and Freddy Fender (side 4)

Budapest String Quartet (J. Roisman and A. Schneider, violins; B. Kroyt, viola; M. Schneider, cello)

It is still too early to assess the impact that these revisions will have on cataloguers' practices. Given the latitude allowed by RDA on how to record statements of responsibility, it is likely that the music cataloguing community will want to adopt best practices that will guide cataloguers and encourage some consistency in approaches. The impact of the revision will therefore be more or less significant depending on how far these best practices will move away from current practices.

\section{Extent of notated music}

At 3.4.3.2 (Recording Extent of Notated Music), the exception for resources consisting of a score and one or more parts in a single physical unit was expanded to also cover resources consisting of multiple parts in a single physical unit. The following examples were added to illustrate the instructions:

1 score and 2 parts ( 1 volume (unpaged))

3 parts $(5,5,5$ pages)

\section{Parts printed in 1 volume with duplicate pagings}

20 parts (approximately 100 pages)

A paragraph was added to connect the instruction with 3.21.2.5:

Make a note to explain the extent, if considered important for identification or selection (see 3.21.2.5).

The scope of 3.21.2.5 was in turn expanded. Its wording was also simplified and new examples added. The instruction now reads thus: 


\section{Score and One or More Parts, or Multiple Parts in a Single Physical Unit}

Make a note giving the number and types of units included in a single physical unit if considered important for identification or selection.

\section{EXAMPLE}

4 parts in 1 volume

1 score and 2 parts in 1 volume; parts printed on leaves 8-10

\section{Duration}

The instructions on duration at 7.22 were thoroughly revised. The distinction that existed before between playing time, running time, etc., for audio and video resources and performance time for notated music was removed and the instructions were generalized to apply to both types of duration. As a consequence, 7.22.1.4 (Performance Time) was deleted and the definition of duration at 7.22.1.1 was modified to reflect the new organization. It now says that "duration is the playing time, running time, performance time, etc., of the content of a resource." It should be noted that performance time is no longer limited to notated music. As some of the new examples show, it now extends to other types of notated content that have a duration, such as plays, monologues, choreographies, etc.

7.22.1.3 was renamed "Recording Duration" and now allows for more flexibility by saying to "record the duration in the form preferred by the agency creating the data." This leaves an agency the choice, for example, to use symbols (e.g., "3 min, $23 \mathrm{~s}$ "), terms (which must then be abbreviated as instructed in appendix B, e.g., "40 min.") or numerals separated by colons (e.g., "2:30:04").

The methods for recording total duration were simplified and no longer give preference to the duration as stated on the resource. The preferred method is to record the exact time if readily ascertainable, whether it is stated on the resource or not. When the playing time is stated on the resource but differs significantly from the actual time, cataloguers no longer have the option to record the stated time followed by that is and the actual time. Now the exact time is recorded and the stated time is given as details, if considered important for identification or selection. If the exact time is not readily ascertainable, an approximate time that is stated or can be readily estimated is recorded, preceded by approximately. Duration is omitted if the time cannot be readily ascertained or estimated. The alternative to give the uniform playing time, running time, etc., of each unit in a multipart resource followed by each was deleted. This information can however still be recorded as details on duration if deemed useful. 
The instruction on duration of individual parts, previously at 7.22.1.5, was moved up to 7.22.1.4 and is now called "Duration of Component Parts," to clarify that it applies to units of intellectual content, such as the songs on a compact disc or the acts of a play, and not to physical units. An alternative was added that allows recording the total duration of the resource instead of or in addition to the duration of the component parts.

A new instruction on details of duration was added at 7.22.1.5., with examples such as the following:

16:00 per audio cylinder

\section{Duration of each cylinder in a set of $\mathbf{3 1}$ audio cylinders}

Running time given as 155 min. on container

Duration stated on resource that has an actual duration of $113 \mathrm{~min}$.

Finally, 7.22.1.6 (Resource Containing Both Sound and/or Moving Images and Text, Still Images, Etc.) was deleted.

\section{Preferred titles for musical works}

Instructions on choosing and recording preferred titles for musical works at 6.14.2 were significantly revised to present a more logical structure and to ensure that their wording is aligned as much as possible with the wording of 6.2.2. ${ }^{2}$ First, 6.14.2.2 (Sources of Information) was modified to make changes similar to those made at the general instruction 6.2.2.2 on sources of information for the preferred title of the work. The existing instructions, which specified the sources to use depending on whether the work was created after 1500 or before 1501 , were replaced by general instructions that apply to all works, regardless of the time of their creation. According to these instructions, the preferred title of a musical work must be determined from resources embodying the work or from reference sources. A sentence was added about applying 6.14.2.3 when choosing the source of information. Existing instructions have not disappeared, but were incorporated in new instructions, i.e. 6.14.2.3.1 and 6.14.2.3.2.

6.14.2.3 (Choosing the Preferred Title for a Musical Work) now has a completely different look. The instruction previously consisted of a rule applying to works of all periods and said to choose "the composer's original title in the language in which it was presented." The rule was then followed by three exceptions: "Better known title in the same language," "Long titles," and

2. For a comparison of the structure of the instructions in 6.14 .2 before and after the April 14 update, see Table 1 at the end of this article. 
"Numbered sequence." 6.14.2.3 now takes the form of a general rule referring to two subinstructions dealing with works created after 1500 (6.14.2.3.1) and works created before 1501 (6.14.2.3.2). This revision resulted in 6.14.2.3 adopting the same structure as the general instructions 6.2.2.3-6.2.2.5. The specific instructions on sources of information that were previously at 6.14.2.2 were rewritten to align with the wording of 6.2.2.4-6.2.2.5 ("choose as the preferred title the title or form of title in the original language by which the work is commonly identified ...") and are now found at 6.14.2.3.1-6.14.2.3.2. As a result this revision better allows for the principle of representation to be respected by explicitly giving priority to a title (or a form of title) by which the work is commonly known, rather than to the composer's original title.

Despite appearances, this does not represent a major change from previous instructions, since the first exception under 6.14.2.3 instructed cataloguers to choose as the preferred title another title in the same language by which the work has become better known instead of the composer's original title. The exception about choosing a brief title by which the work is commonly identified in reference sources also gave priority to a better known title. The revision has the advantage of making the instructions more consistent by rewriting the instruction formerly at 6.14.2.3 in the same terms as the general instructions 6.2.2.4-6.2.2.5. Also, by making the exception the rule, the revision now emphasizes the principle of representation.

To provide for cases where it is not possible to choose as the preferred title the title or form of title in the original language by which the work is commonly identified, an instruction was added at 6.14.2.3.1 indicating to instead choose as the preferred title the composer's original title or the title of the original edition, in that order of preference. This instruction is applied when "there is no title or form of title in the language originally used by the composer established as the one by which the work is commonly identified," when "the language of the title originally used by the composer cannot be established" as well as in case of doubt.

Following these changes, the exceptions asking to choose a title in the same language by which the work is better known or a brief title by which the work is commonly identified in reference sources became redundant, and so they were deleted. The exception about choosing a brief title devised by the cataloguer instead of a very long title was deemed incompatible with the principle of representation and it was also deleted. Because the exception about works belonging to a numbered sequence of works deals not with choosing, but with recording the preferred title, it was moved to 6.14.2.5 (Recording the Preferred Title for an Individual Musical Work). 
Reflecting the fact that special instructions were added at 6.2.2 to address cases where a title in the original language is not found or is not applicable (6.2.2.6) and where a title is found in a non-preferred script (6.2.2.7), relevant references to these instructions were included at both 6.14.2.3.1 and 6.14.2.3.2.

6.14.2.4-6.14.2.5 were revised to fill various gaps. 6.14.2.4 was a general rule about recording preferred titles, but was actually meant to apply only to individual works. The instruction was rewritten to have a truly general scope and now explicitly states that it applies to both individual works and compilations of works. It now includes a rule asking not to record an alternative title as part of the preferred title, modelled on the equivalent rule at 6.2.2.8 (previously at 6.2.2.4). The paragraphs about the elements to omit from the title were moved under 6.14.2.5.1.

At 6.14.2.5, there is now a new instruction on recording the preferred title of an individual musical work which refers back to 6.14.2.4. The exception previously at 6.14.2.3 on numbered sequences of works was moved there, and for clarity, was reworded with three conditions instead of two. Instructions on omissions (6.14.2.5.1, previously 6.14.2.4) and those on preferred titles consisting solely of the name of one type of composition (6.14.2.5.2, previously 6.14.2.5) now appear as sub-instructions of 6.14.2.5 to clarify that they apply only to individual works and not to compilations.

Two changes that affect the elements to omit from the preferred title given at 6.14.2.5.1 are worth noting. The wording of paragraph d) now specifies that the numbers in question are cardinal and ordinal numbers to distinguish this paragraph from the preceding paragraph (serial, opus, and thematic numbers). Paragraph f) previously at 6.14.2.4 on omitting "adjectives and epithets not part of the original title of the work" was deleted since such terms should not logically be part of the preferred title chosen according to 6.14.2.3. The examples of omissions at 6.14.2.5.1 were revised to make them more consistent with the editorial principles followed in RDA. Among other things, notes were added to explain the application of the instruction and its exceptions, as in the following examples:

Präludien und Fugen

Preferred title before omissions: Sechs Präludien und Fugen für Organ. Number and statement of medium of performance omitted

The seventh trumpet

Number recorded because it is an integral part of the title 
For clarity, the counterexamples were grouped together at the end and are clearly identified as such by the preposition but that precedes them.

It is worth noting two revisions affecting the sub-instructions of 6.14.2.5.2. At 6.14.2.5.2.1, the exception for works called étude, fantasia, sinfonia concertante or their cognates no longer specifies that it applies only to works intended for concert performance. This distinction was no longer considered necessary or appropriate and so it was eliminated. At 6.14.2.5.2.2, the notes accompanying the examples were rewritten to summarize and make more explicit the various stages through which a title could go before reaching the form finally recorded. An example is:

Quartet

Preferred title before omissions: Quatuor pour 2 hautbois et 2 bassons. Title after omissions: Quatuor. English language form recorded by an English-language agency in Canada because it is a cognate to the French title

Finally, it should be noted that instruction 6.14.2.6 (Duets) was deleted. Besides being difficult to justify in an international code, standard usage of the term Duet for works variously titled duos, duets, etc. did not respect the principle of representation which requires that the form of title chosen as the preferred title be the one that is the most commonly used to identify the work.

\section{Abbreviations in titles for parts of musical works}

Instructions 6.2.1.9 and B.3, which govern the usage of abbreviations in titles of works, were expanded to allow for the abbreviation for the word Number or its equivalent in another language. Number or its equivalent can now be abbreviated, but only when it appears "in the title for a part of a musical work [and] when this word precedes a number used to identify that part." The following example was added to illustrate this:

Nr. 32, Sheherazade

\section{Title for a part of a musical work}

This practice was followed by U.S. cataloguers under AACR2 and is derived from the Library of Congress Rule Interpretation (LCRI) for AACR2 rule 25.32A1. The JSC felt it would be useful to incorporate this practice in RDA. The LCRI also gave guidance on how to record a number that identifies a part of a musical work and what to do when that number is not preceded by a term such as Number. This guidance was incorporated into 6.14.2.7.1 (One Part), which includes new text saying: 
Record a number used to identify the part as a numeral. If the number of the part has no general term associated with it, precede the number with the abbreviation for Number or its equivalent in another language (see appendix B (B.3)). Record the abbreviation in the language in which the preferred title of the work as a whole is recorded.

\section{Access points representing musical expressions}

The revision of 6.28.3 (renamed Constructing Authorized Access Points Representing Musical Expressions) was primarily aimed at broadening the scope of the instruction, which was limited to the types of musical expressions listed at 6.28.3.1, namely:

a) arrangements, transcriptions, etc.

b) added accompaniments, etc.

c) sketches

d) vocal and chorus scores

e) translations

For other types of musical expressions, RDA instructed us to apply the general instructions at 6.27.3 (Authorized Access Point Representing an Expression), which allow including the content type, the date of the expression, the language of the expression and/or another distinguishing characteristic of the expression in an access point representing a particular expression of a work or of a part or parts of a work. There was however no instruction that would have allowed using any of these elements for the musical expressions covered at 6.28.3.1. In addition, the instruction had no provision for cases where an expression belonged to more than one of the types that it specifically covered (for example, a vocal score that would also be a translation). 6.28.3 was revised to remove these restrictions and allow the addition of one or more of the following elements:
a) the content type
b) the date of the expression
c) the language of the expression
d) another distinguishing characteristic of the expression of a musical work

The instruction was also simplified to reduce redundancy both within the instruction itself and with other instructions, mostly 6.18. It is now reduced to a single instruction, modelled on 6.27.3, which lists the elements that can be combined with the authorized access point representing the work or the part or parts of a work in order to construct an access point representing a particular expression of a work or a part or parts of a work. References now guide the cataloguer to the instructions for the specific elements $(6.9,6.10,6.11$ and 6.18$)$ for 
further guidance on how to record them. An appropriate reference was also added at the end of 6.27.3 to lead cataloguers to 6.28.3.

In turn, this revision generated changes to 6.18 (Other Distinguishing Characteristic of the Expression of a Musical Work). The definition of the element was extended to allow recording attributes other than the terms arranged, Sketches, Vocal score, Vocal scores, Chorus score or Chorus scores. The new definition, whose wording is borrowed from that used at 6.12.1.1 for the element "Other Distinguishing Characteristic of the Expression," now specifies that it "is a characteristic other than content type, language of expression, or date of expression." It should therefore provide cataloguers with more flexibility when recording attributes of musical expressions.

The instructions for arrangements, transcriptions, etc. were also revised. 6.18.1.4 was rewritten to take the form of a general rule for all arrangements, etc., and not only to the category of "serious," "classical" or "art" music. The paragraphs stating the categories of expressions covered by the instruction were rewritten to align with the definition of arrangement in the glossary. The instruction now applies when an expression results from "a change in the medium of performance or a simplification or other modification of the work, with or without a change in medium of performance." The instruction on arrangements, etc., in the "popular" idiom, previously at 6.18.1.4.1, is now treated as an exception to the general instruction. Because the instruction on added accompaniments, etc., previously at 6.28.3.3, had no equivalent in 6.18 , a second exception was added at 6.18.1.4 instructing not to record arranged if an instrumental accompaniment or additional parts were added to a work or a part or parts of a work and the original music was not altered.

\section{Conclusion}

The updates discussed in this article are part of the ongoing work the JSC is doing to ensure that instructions derived from AACR2 - especially music-related instructions-are adapted to the context of RDA, that inconsistencies between instructions are resolved and that gaps are filled. All these revisions will not have an equal or necessarily visible impact in bibliographic records. Some of the changes will be more likely than others to be noticed and, hopefully, appreciated by catalogue users. However, revisions that were focused on simplifying instructions or improving their structure rather than changing their outcome are no less important, because it is hoped that they will make learning and applying RDA easier. 


\section{TABLE 1}

Comparison of the structure of 6.14.2 instructions before and after the April 14, 2015 update

Note: The sub-instructions of 6.14.2.7 have not been affected by the reorganization of 6.14.2 and have not been included in the table.

\begin{tabular}{|c|c|c|}
\hline Structure before the update & \multicolumn{2}{|r|}{ Structure after the update } \\
\hline 6.14.2 Preferred Title for a Musical Work & 6.14 .2 & referred Title for a Musical Work \\
\hline 6.14.2.1 Scope & 6.14.2.1 & Scope \\
\hline 6.14.2.2 Sources of Information & 6.14.2.2 & Sources of Information \\
\hline $\begin{array}{l}\text { 6.14.2.3 Choosing the Preferred Title for a } \\
\text { Musical Work }\end{array}$ & 6.14 .2 .3 & $\begin{array}{l}\text { Choosing the Preferred Title for a } \\
\text { Musical Work }\end{array}$ \\
\hline & 6.14.2.3.1 & Musical Works Created after 1500 \\
\hline & 6.14.2.3.2 & Musical Works Created Before 1501 \\
\hline $\begin{array}{l}\text { 6.14.2.4 Recording the Preferred Title for a } \\
\text { Musical Work }\end{array}$ & 6.14 .2 .4 & $\begin{array}{l}\text { Recording the Preferred Title for a } \\
\text { Musical Work }\end{array}$ \\
\hline & 6.14 .2 .5 & $\begin{array}{l}\text { Recording the Preferred Title for an } \\
\text { Individual Musical Work }\end{array}$ \\
\hline & 6.14.2.5.1 & Omissions \\
\hline $\begin{array}{l}\text { 6.14.2.5 Preferred Title Consisting Solely of the } \\
\text { Name of One Type of Composition }\end{array}$ & 6.14 .2 .5 .2 & $\begin{array}{l}\text { Preferred Title Consisting Solely of } \\
\text { the Name of One Type of } \\
\text { composition }\end{array}$ \\
\hline 6.14.2.5.1 Choice of Language & 6.14.2.5.2.1 & Choice of Language \\
\hline 6.14.2.5.2 Singular or Plural Form & 6.14.2.5.2.2 & Singular or Plural Form \\
\hline 6.14.2.6 Duets & 6.14.2.6 & Duets [deleted] \\
\hline $\begin{array}{l}\text { 6.14.2.7 Recording the Preferred Title for a Part } \\
\text { or Parts of a Musical Work }\end{array}$ & 6.14.2.7 & $\begin{array}{l}\text { Recording the Preferred Title for a Part } \\
\text { or Parts of a Musical Work }\end{array}$ \\
\hline 6.14.2.8 Compilations of Musical Works & 6.14 .2 .8 & Recording the Preferred Title for a \\
\hline $\begin{array}{ll}\text { 6.14.2.8.1 Recording the Preferred Title for } \\
\text { Compilations of Musical Works }\end{array}$ & & $\begin{array}{l}\text { Compilation of Musical Works by One } \\
\text { Composer }\end{array}$ \\
\hline 6.14.2.8.2 Complete Works & 6.14.2.8.1 & Complete Works \\
\hline $\begin{array}{l}\text { 6.14.2.8.3 Complete Works for One Broad } \\
\text { Medium }\end{array}$ & 6.14.2.8.2 & $\begin{array}{l}\text { Complete Works for One Broad or } \\
\text { Specific Medium }\end{array}$ \\
\hline $\begin{array}{ll}\text { 6.14.2.8.4 Complete Works for One Specific } \\
\text { Medium }\end{array}$ & & \\
\hline $\begin{array}{ll}\text { 6.14.2.8.5 Complete Works of One Type for One } \\
\text { Specific Medium or Various Media }\end{array}$ & 6.14.2.8.3 & $\begin{array}{l}\text { Complete Works of a Single Type of } \\
\text { Composition for One Specific Medium } \\
\text { or Various Media }\end{array}$ \\
\hline 6.14.2.8.6 Incomplete Compilations & 6.14.2.8.4 & Incomplete Compilations \\
\hline
\end{tabular}

